\title{
PENINGKATAN KOMPETENSI MENGAJAR GURU-GURU PAUD DI WILAYAH KECAMATAN BLIMBING KOTA MALANG DENGAN PELATIHAN KOMPUTER DAN MULTIMEDIA
}

\author{
Nurhadi $^{1}$, Santoso $^{2}$, Kasijanto $^{3}$ \\ 1,2,3 Jurusan Teknik Mesin, Politeknik Negeri Malang \\ nurhadiabuzaka@gmail.com
}

\begin{abstract}
ABSTRAK
Latar belakang kegiatan Pengabdian kepada Masyarakat (PkM) adalah adanya permasalahan yang dialami guru-guru PAUD di Kecamatan Blimbing Kota Malang dalam menjalankan sistem dan proses pendidikan, dimana skill pemamfaatan teknologi komputer dan multimedia masih lemah. Sistem administrasi surat menyurat, sistem keuangan, dan lain-lain seringkali mengalami hambatan karena masih dilakukan secara manual, sehingga hasilnya kurang optimal. Peralatan multimedia LCD proyektor dan power point untuk presentasi belum dimanfaatkan dengan baik pada proses pembelajaran, sehingga pembelajaran kurang menyenangkan. Tujuan PkM adalah memberikan pengetahuan dan ketrampilan/skill komputer dan multimedia kepada Guru PAUD agar mampu memperbaiki sistem administrasi PAUD dan mengembangkan proses pembelajaran. Metode pelaksanaan kegiatan PkM dengan menyelenggarakan pelatihan komputer multimedia berupa mail merge, formula excell, power point, pengoperasian dan perawatan LCD proyektor, baik teori maupun praktek. Pelatihan dilaksanakan di Gedung PKBM Zamzam, tanggal 8,15 dan 22 April 2017, diikuti oleh 30 Guru PAUD. Karya utama dari kegiatan PkM ini yaitu peningkatan soft skill 30 Guru PAUD di wilayah Kec. Blimbing Kota Malang, berupa peningkatan kemampuan membuat surat beserta alamatnya secara otomatis dengan program mail merge, membuat sistem akuntansi dan laporan keuangan dengan formula excell, membuat presentasi pembelajaran multimedia dengan power point, serta mengoperasikan dan merawat LCD proyektor. Dampak kegiatan PKM yaitu meningkatnya pengetahuan dan skill Guru-guru PAUD di wilayah Kec. Blimbing Kota Malang tentang pemamfaatan teknologi komputer dan multimedia dalam pembelajaran, sehingga memudahkan proses pembelajaran dan pengelolaan lembaga PAUD. Manfaat yang diperoleh para Guru PAUD dari kegiatan PkM berupa peningkatan pengetahuan dan skill pemamfaatan teknologi komputer dan multimedia dalam pembelajaran, memudahkan proses pembelajaran dan pengelolaan lembaga PAUD. Kesimpulannya bahwa kegiatan PkM berupa Pelatihan komputer dan mulimedia bagi Guru PAUD di wilayah Kec. Blimbing Kota Malang dapat meningkatkan pengetahuan dan skill Guru PAUD untuk memamfaatkan teknologi komputer dan multimedia dalam pembelajaran sehingga memudahkan proses pembelajaran dan pengelolaan PAUD.
\end{abstract}

Kata kunci: komputer, multimedia, Guru PAUD

\begin{abstract}
The background of Community Service Activity (CSA-PkM) is a problem has been exist on preschool (PAUD) teachers in district Blimbing, Malang City in running the system and education process, especially low skill in using computer and multimedia technology and education management. Mail administration system, financial system or report and others, often obstacles because it is still done manually, so the result is less than optimal. LCD projector multimedia equipment and power point for presentation have not been well utilized in learning process, so the learning process is not enjoyable. The purpose of PkM is to provide knowledge and skills / computer skills and multimedia to preschool teachers to be able to improve PAUD administration system and develop the learning process.The Method which implement in this activities (PkM) is conducted a multimedia computer training in the form of mail merge, formula excell, power point, operation and maintenance LCD projector, both theory and practice. The training was held at PKBMZamzam Building, dated 8,15 and 22 April 2017, followed by 30 PAUD Teachers. This PkM condusted to improve the soft skill of 30 PAUD teachers in district Blimbing, Malang City, about their ability to create formal letters including the addresses automatically by mail merge program, create accounting system and financial report by excell formula, create multimedia learning presentation by power point, and operate and maintain the LCD projector.The impact of PKM activity is increasing knowledge and skill/ability of PAUD teachers in district Blimbing, Malang City, in utilizing computer technology and multimedia in learning process, thus facilitating the process of learning and management of early PAUD institutions. Benefits obtained by PAUD teachers from PkM activities in the form of increased knowledge and skills of computer technology and multimedia utilization in learning, facilitate the process of learning and management of early PAUD institutions. The conclusion that the PkM activities in the form of Computer Training and
\end{abstract}


Nurhadi, Peningkatan Kompetensi Mengajar Guru-Guru Paud...

Mulimedia for PAUD Teachers in district Blimbing, Malang City can improve the knowledge and skill of PAUD teachers to utilize computer technology and multimedia in learning so as to facilitate the learning process and management of PAUD.

Keywords: computer, multimedia, PAUD Teachers

\section{PENDAHULUAN}

Kegiatan PkM ini dilatarbelakangi masih lemahnya kompetensi Guru PAUD dalam mengajar dan mengelola pendidikan menggunakan komputer dan multimedia. Di wilayah Kecamatan Blimbing Kota Malang, Guru-guru PAUD tergabung dalam wadah Perhimpunan PAUD Indonesia (Himpaudi) Blimbing. Permasalahan yang masih banyak dialami para guru PAUD tersebut adalah masih lemahnya skill dalam pemamfaatan teknologi komputer dan multimedia, sehingga sistem administrasi dan proses pembelajaran seringkali mengalami hambatan. Misalnya administrasi surat menyurat, sistem keuangan, dan lain-lain masih dilakukan secara manual. Meskipun sudah menggunakan komputer, pemanfaatan fungsinya juga belum optimal. Pada proses pembelajaran, peralatan multimedia seperti LCD proyektor, power point untuk presentasi belum dimanfaatkan dengan baik, sehingga proses belajar berjalan monoton dan kurang menarik. Peningkatan skill Guru PAUD dalam mengajar dan mengelola pendidikan dengan peralatan komputer multimedia dilakukan dengan memberikan pelatihan teori dan praktek aplikasi komputer multimedia yang relevan.

\section{METODE}

Metode yang dipilih untuk dilaksanakan pada PKM ini yaitu Pendampingan Masyarakat dengan memberikan pelatihan teori dan praktek komputer dan multimedia, meliputi Pelatihan komputer (Mail merge, Akuntansi sederhana dengan MS. Excell), Pelatihan Multimedia (membuat presentasi yang menarik dengan MS. Power point, pengoperasian dan perawatan LCD proyektor).

Mail merge adalah fasilitas pada $M S$ word yang dapat digunakan untuk mencetak beberapa dokumen yang berasal dari satu dokumen word yang sama, tetapi beberapa isinya berubah-ubah. Misalnya saat membuat dan mencetak undangan, sertifikat, dll, dimana bentuknya sama, tetapi nama, dan alamat berubah-ubah, maka hal itu dapat dilakukan dengan mudah tanpa harus menulis satu persatu secara manual, tetapi menggunakan bantuan fasilitas mail merge. Fasilitas ini paling banyak digunakan oleh oleh para sekretaris dan admin kantor untuk membuat surat undangan, membuat sertifikat, amplop, dan lain-lain. Dengan fasilitas mail merge, surat undangan, membuat sertifikat, amplop, dan lain-lain dapat dikerjakan dengan cepat dan rapi sehingga dapat meningkatkan efisiensi waktu pekerjaan. (Anonim, 2013:1).

Microsoft Excell banyak digunakan untuk membantu dalam rangka memudahkan pembuatan laporan keuangan. Meski dengan berjalannya waktu hal ini semakin berkurang dengan semakin banyaknya software akuntansi yang dibuat secara khusus. (Anonim, 2015:1-2).

Penggunaan sarana multimedia misalnya MS power point dalam pembelajaran sangatlah penting, khususnya untuk membuat presentasi. Dalam presentasi apapun dan dimanapun, termasuk dalam menyampaikan materi pelajaran di sekolah, khususnya bagi anak usia dini (PAUD), animasi sangatlah penting. Animasi bukanlah mainan yang hanya sekedar menambahkan efek supaya text/gambar bisa bergerak, melayang-layang. dan sejenisnya. Tujuan penggunaan presentasi multimedia bukanlah itu saja, melainkan untuk membuat presentasi pembelajaran menjadi lebih mudah difahami dan lebih menarik untuk disimak. (Thovids, 2015:1-4). Dalam penggunaan sarana multimedia dalam pembelajaran, tidak bisa dilepaskan dengan pengoperasian LCD proyektor. Setiap guru, khususnya guru PAUD yang ingin menyampaikan materi pelajaran dengan menarik, harus mampu mengoperasikan peralatan tersebut dengan baik. Dalam menggunakan dan merawat sebuah LCD proyektor sebagaimana Gambar 1, tentunya tidak boleh dilakukan dengan asal-asalan, sebab alat ini tergolong mudah rusak. Karena itu, agar LCD proyektor anda awet alias tahan lama, maka pemakai perlu memperhatikan dalam penggunaan dan perawatannya. (Wahyu, 2011:1). 


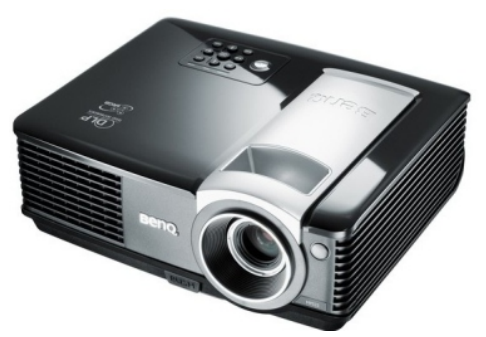

Gambar 1. LCD Projector

Adapun metode pelaksanaan dalam kegiatan $\mathrm{PkM}$ ini diilustrasikan pada diagram alir sebagaimana Gambar 2.

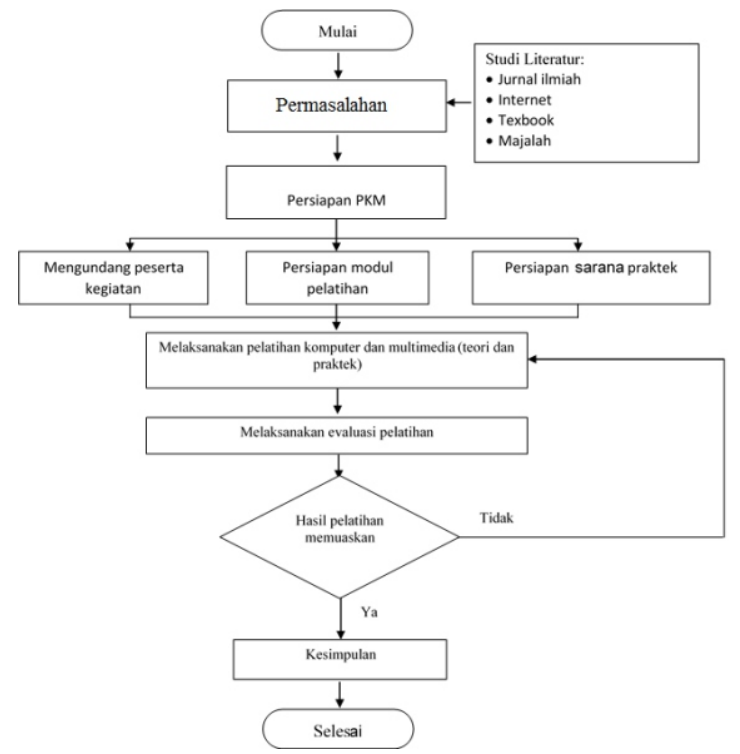

Gambar 2. Diagram alir kegiatan PkM

\section{HASIL DAN PEMBAHASAN}

Kegiatan PkM berupa Pelatihan Komputer dan Multimedia bagi Guru PAUD ini dilaksanakan dengan beberapa tahapan, yaitu tahap persiapan, pelaksanaan dan evaluasi.

\section{Tahap Persiapan Kegiatan}

Tahap persiapan kegiatan ini meliputi koordinasi internal Tim PkM, koordinasi eksternal dengan lembaga Mitra (Himpaudi Blimbing), penyiapan modul pelatihan, penyiapan sarana prasana praktek. dan penyiapan brosur/undangan pelatihan.

Koordinasi internal Tim dilakukan untuk membuat rencana pelaksanaan kegiatan dan evaluasinya. Koordinasi eksternal dilakukan untuk memberitahukan rencana kegiatan kepada mitra PkM dan memastikan bahwa mitra siap mengikuti kegiatan yang dijadwalkan.

Penyiapan modul pelatihan dilakukan oleh Tim PkM dengan modul pelatihan komputer multimedia yang berisi materi: pembuatan surat otomatis dengan mail merge, pembuatan laporan keuangan dan akuntansi keuangan dengan formula excell, pembuatan presentasi pembelajaran dengan power point dan pengoperasian serta perawatan LCD proyektor. Setiap topik/materi pelatihan tersebut dilengkapi dengan tugas untuk peserta pelatihan.

Penyiapan sarana praktek meliputi penyiapan komputer/laptop yang dilengkapi dengan software/aplikasi sesuai kebutuhan, penyiapan steker listrik dalam jumlah yang cukup, dan penyiapan LCD proyektor beserta kelegkapannya, dan penyiapan peyiapan tempat pelatihan. 
Tempat pelatihan dicarikan tempat yang representatif untuk pelatihan, yaitu menyewa Aula PKBM Zamzam Jl. Polowijen.

Penyiapan brosur/undangan dilakukan dengan membuat brosur/informasi kegiatan pelatihan komputer dan multimedia kepada Guru PAUD yang disebar secara langsung maupun melalui grup Whatsapp (WA) Himpaudi Blimbing. Persiapan tempat dan brosur pelatihan sebagaimana Gambar 3.

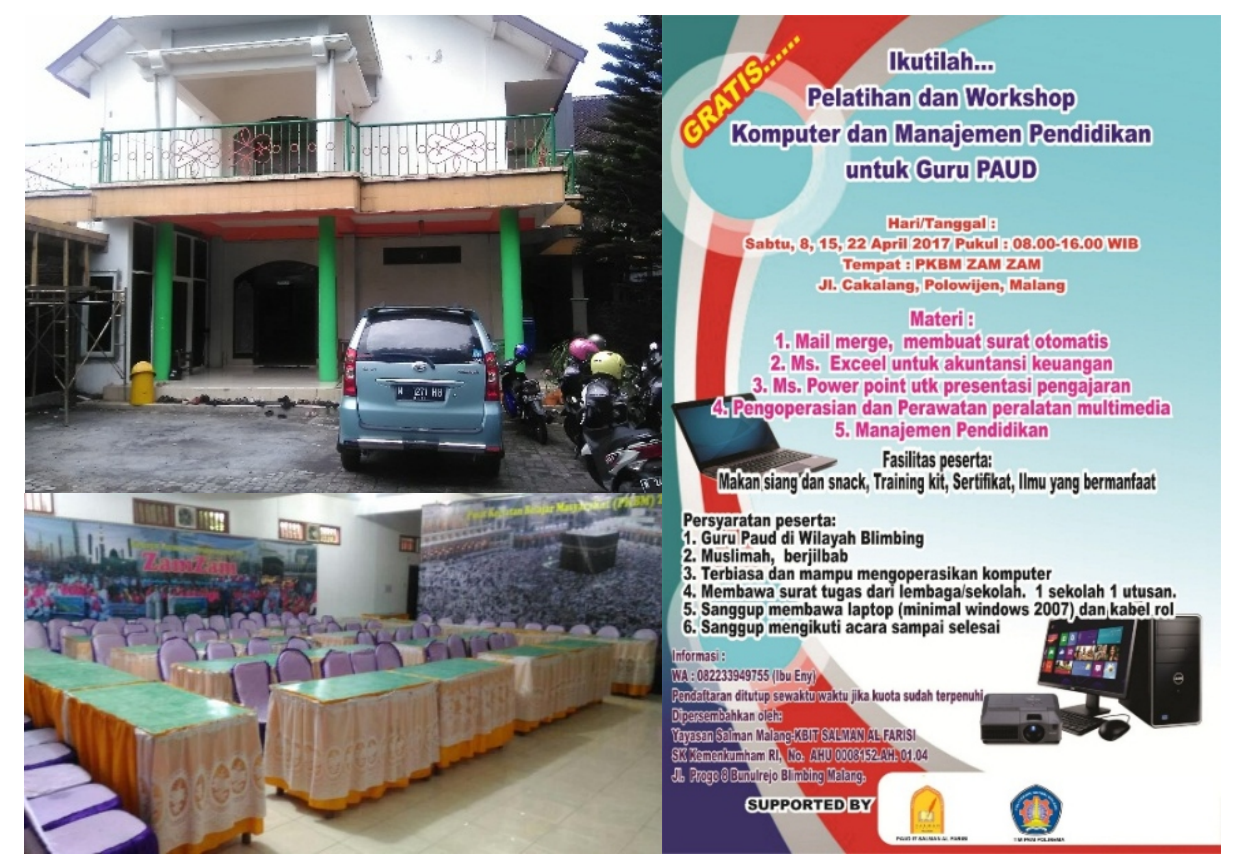

Gambar 3. Tempat dan brosur pelatihan

\section{Tahap Pelaksanaan Kegiatan}

Pelaksanaan kegiatan Pelatihan Komputer dan Multimedia bagi Guru PAUD ini berupa pelatihan teori dan pelatihan praktek.

\subsection{Pelatihan teori}

Pelatihan dilaksanakan didalam kelas/Gedung Aula PKBM Zamzam, Jl. Polowijen Blimbing Malang, selama 3 hari, setiap hari Sabtu, tanggal 8, 15 dan 22 April 2017. Pelatihan dilakukan pada hari Sabtu agar para Guru PAUD dapat mengikuti pelatihan tanpa harus meninggalkan jam mengajar. Selain itu agar materi yang diperoleh pada hari pertama dapat dipraktekkan di rumah sebelum peserta mendapatkan materi berikutnya. Pada hari pertama diberikan materi Mail merge dan Formula Excell. Mail merge adalah materi materi yang diperlukan untuk membuat surat undangan otomatis dengan nama/alamat yang berbeda-beda. Formula Excell diperlukan untuk membuat Laporan keuangan PAUD dengan baik. Pada hari kedua diberikan materi MS Power point dan Multimedia. MS Power point untuk membuat presentasi pengajaran yang menarik, pengoperasian dan perawatan LCD proyektor. Hal ini dimaksudkan agar para guru PAUD tidak gagap teknologi (gaptek) dengan teknologi multimedia dalam pengajaran. Pada hari ketiga diberikan materi Manajemen Pendidikan, dengan fokus manajemen kelas, agar para Guru PAUD dapat mengatur dan mengelola kelas dengan baik. Pengajar atau instruktur pelatihan komputer Multimedia yaitu Tim PkM Polinema, sedangkan Manajemen Pendidikan diberikan oleh Pakar Manajemen Pendidikan dari Lembaga Pendidikan Insan Permata Malang.

Pendaftar pelatihan ini yang mendaftar ke panitia melalui Grup WA Himpaudi Blimbing sebanyak 30 Guru PAUD, sedangkan pendaftar yang hadir pada saat pelatihan juga sebanyak 30 orang, namun ada beberapa nama yang berubah karena berhalangan atau digantikan sesama Guru dalam satu sekolah yang sama. Daftar peserta pelatihan dan dokumentasi kegiatan sebagaimana Gambar 4 dan 5. 
Jurnal Aplikasi dan Inovasi Ipteks, Vol. 1 / No. 1 / April 2018 ; 1-10

Daftar peserta pelatihan komputer dan multimedia

\begin{tabular}{|c|c|c|}
\hline No & NAMA & ASAL LEMBAGA \\
\hline 1 & ANI MUTMAINAH & PP SEDAP MALAM PANDANWAN GI \\
\hline 2 & ANISAH AULIYAH & KB/TK AL FATH BUNULREOO \\
\hline 3 & CHOIRIYAH, S.PdI & KB PERHARSIA TUJUH TA MAN SULFAT III/ 6 \\
\hline 4 & ERNA WIDI ASTUTIK & KB BAIPAS CERIA \\
\hline 5 & HENDAH SUUSTYOWTI & PP CENDEKIA \\
\hline 6 & IDA NURULAINI & PP AL IKHLAS \\
\hline 7 & INDAH MUSTIKAWATI, & TK/PRA TK UNGGULAN AL YA'LU \\
\hline 8 & IRA SANTIW & KB IPANK KIDS \\
\hline 9 & LAILA FADHILAH & KB AL JABBAR \\
\hline 10 & LAILATUL KHOJANNAH & KB ZAMZA M POLOWIJEN \\
\hline 11 & LILIK PUDJI LESTARI & PP MENUR POLEHAN \\
\hline 12 & MAISUNAH & TPA/KB/TK PLUS ANAK MUSLIM \\
\hline 13 & MA RDIANA DEWI K. & CHEVIRA KIDS \\
\hline 14 & MEYTA RENANINGTYAS & PP PELANGI POLOWIJEN \\
\hline 15 & MIA NISSA FITRIA NI & KB AT TIBYAN PANDANWANGI \\
\hline 16 & NURUL IRAWATI & KB AL AZHAR \\
\hline 17 & OKTORINA & KB PER MATA HATI \\
\hline 18 & RETNO HARTAMI & PP ANGGREK PURWODADI \\
\hline 19 & SUTINI & KB KARTIKA RINDAM V/BRW \\
\hline 20 & SYLVIA YUNITA R & PP PERMATA HATI POLOWIJEN \\
\hline 21 & TANTI SETYA VOVI & PP HARAPAN BANGSA \\
\hline 22 & TUTI KUSMIATI, SP & PP KASIHIBU POLEHAN \\
\hline 23 & UMIATUL MUSUSYA & KB QURROTA AYYUN \\
\hline 24 & WAHYU WULANDARI & PP TUNAN BANGSA BLIM BING \\
\hline 25 & WIJI LESTARI & PP PERMATA BUN DA \\
\hline 26 & WITFICHUSNA AVIANI & KB/TK CENDEKIA AGUNG \\
\hline 27 & WULAN & PP SERUNI PUTIH \\
\hline 28 & YUU ANITA, A.Md. & PP SERUNI BALE ARJOSARI \\
\hline 29 & ENY LASTIO WANDARI & KB IT SALMAN AL FA RISI \\
\hline 30 & YUUSTYOWATI, SAB & KB IT SALMAN AL FA RISI \\
\hline
\end{tabular}

Gambar 4. Daftar peserta pelatihan

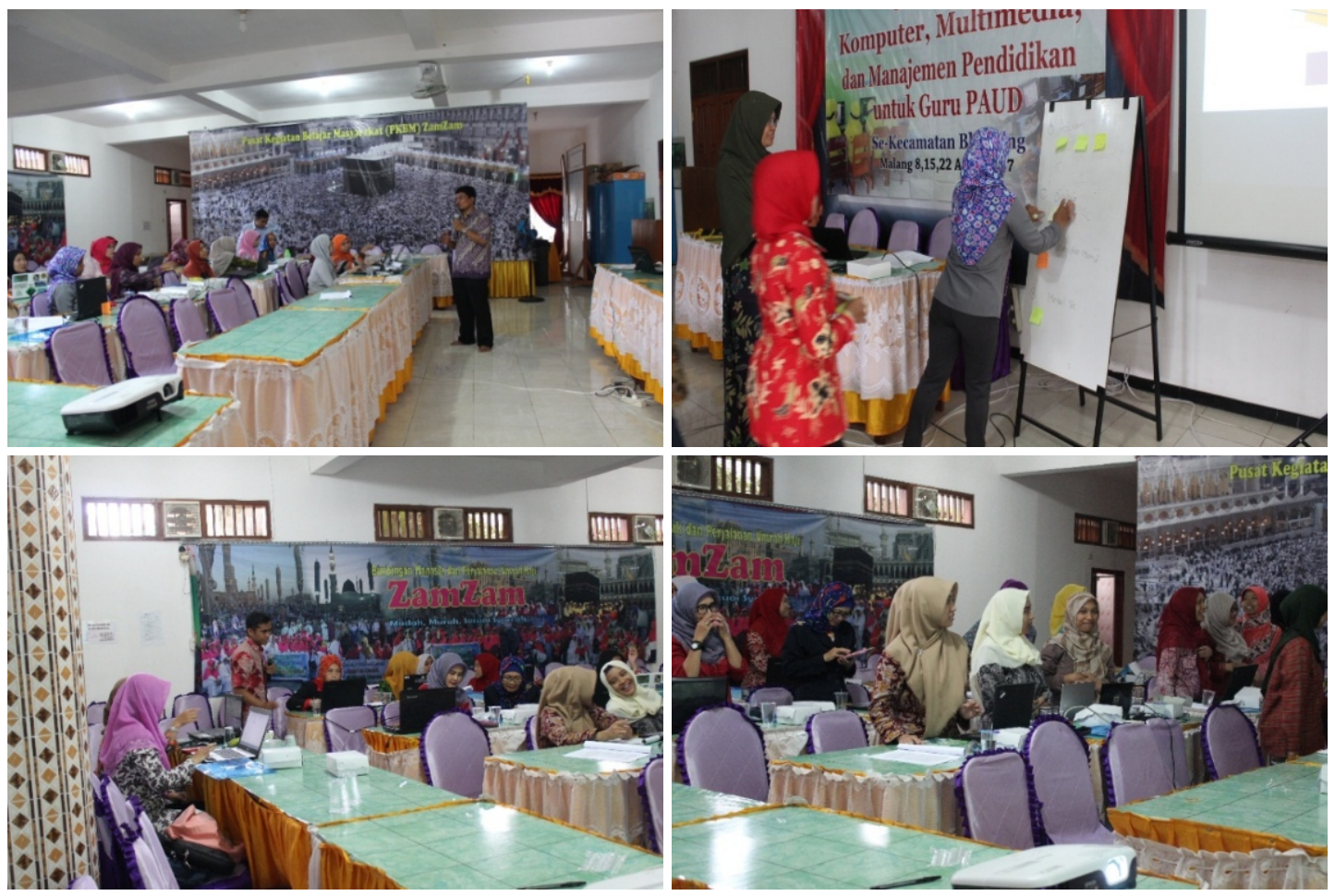

Gambar 5. Dokumentasi kegiatan pelatihan 


\subsection{Pelatihan praktek}

Pada pelatihan praktek, peserta langsung diberikan tugas praktek sesuai topik untuk dikerjakan dan dipandu oleh instruktur, yaitu topic mail merge, formula exell dan membuat presentasi. Sedangkan untuk praktek pengoperasian LCD proyektor, instruktur memberikan tugas kepada peserta secara acak dan peserta yang lain ikut menyaksikannya. Tugas praktek yang diberikan kepada peserta pelatihan adalah sebagai berikut:

\section{Tugas 1 (Topik Mail merge)}

Buatlah surat menyurat resmi dari lembaga PAUD anda dengan 10 nama dan alamat tujuan surat yang berbeda-beda!

Petunjuk:

a) Buatlah terlebih dahulu tabel tujuan surat dengan MS Exceel dengan3 kolom 10 baris yang berisi: No, Nama Tujuan Surat, Alamat Tujuan Surat

b) Buatlah mail merge nya!

\section{Tugas 2 (Topik Formula Excell)}

Buatlah laporan keuangan sederhana dari lembaga dari kegiatan OUTBOUND CLASS PAUD anda yang berisi pemasukan dan pengeluaran serta Saldo, dengan MS EXCEEL.

Petunjuk:

a) Tentukan nama kegiatan

b) Tentukan besaran pemasukan dan pengeluaran

c) Minimal 10 Baris

d) Buat Saldo dengan rumus excell

\section{Tugas 3 (Topik Formula Excell)}

Buatlah nilai harian/rapor siswa PAUD anda menggunakan rumus MS EXCELL.

Petunjuk:
a) Jumlah siswa minimal 10 orang
b) Terdiri dari 4 nilai, yaitu nilai 1,2,3,4 masing-masing dengan angka 50-100
c) Buatlah nilai rata-rata dari nilai 1-4
d) Berikan nilai huruf dari nilai rata-rata tsb menggunakan rumus IF, dengan ketentuan: A (85 $<\mathrm{N} \leq 100), \mathrm{B}(70<\mathrm{N} \leq 85), \mathrm{C}(55<\mathrm{N} \leq 70), 40<\mathrm{N} \leq 55, \mathrm{E}(\leq 40)$

\section{Tugas 4, Topik Power point:}

Buatlah presentasi sederhana dari kegiatan PAUD anda dengan MS Power point yang berisi teks, gambar dan video.

Petunjuk:
a) Jumlah slide Minimal 10 slide
b) Warna background tiap slide berbeda-beda
c) Jenis dan Besar font menyesuaikan (sebaiknya tidak kurang dari 24).
d) Isi tiap slide berupa teks dan gambar
e) Minimal ada 1 video

\section{Tugas 5 (Topik Pengoperasian dan perawatan LCD Proyektor)}

Instruktur memilih salah satu peserta pelatihan secara acak untuk mempraktekkan cara mengoperasikan LCD proyektor mulai dari awal sampai menutup/mematikannya.

\subsection{Tahap Evaluasi}

Pada akhir sesi pelatihan, peserta diberikan kesempatan untuk menyampaikan kesan dan pesan dalam mengikuti pelatihan. Dari beberapa kesan yang disampaikan, rata-rata peserta sangat 
Jurnal Aplikasi dan Inovasi Ipteks, Vol. 1 / No. 1 / April 2018; 1-10

senang dan antusias dalam mengikuti pelatihan, dan menginginkan adanya tindak lanjut pelatihan dengan materi yang berbeda, misalnya materi menggambar dengan komputer yang akan membantu mereka dalam persiapan mengajar PAUD.

Sementara itu untuk mengevaluasi daya serap peserta terhadap materi pelatihan, dilakukan dengan cara instruktur memeriksa hasil peserta dalam mengerjakn tugas praktek yang diberikan. Tugas praktek yang diberikan yaitu: membuat surat undangan otomatis dengan mail merge, membuat laporan keuangan dengan formula excell, membuat presentasi pembelajaran dengan MS power point. dan mengoperasikan LCD proyektor sebagaimana dijelaskan pada bagian sebelumnya.

Dari pengamatan instruktur pada peserta, rata-rata peserta sudah dapat mengerjakan tugas praktek dengan baik.

\subsection{Penutupan Kegiatan}

Pada bagian akhir pelatihan komputer multimedia yang dislenggarakan oleh tim PkM Jurusan Teknik Mesin Polinema ini dilakukan penutupan acara. Upacara penutupan dilakukan secara sederhana, dengan kegiatan Sambutan dan ucapan terimakasih dari ketua panitia kegiatan, penyampaian kesan dan pesan dari peserta, serta doa penutup. Setelah itu dilanjutkan dengan sesi foto bersama dan pengambilan sertifikat pelatihan oleh peserta. Upacara penutupan dan penyerahan sertifikat pelatihan sebagimana Gambar 6.
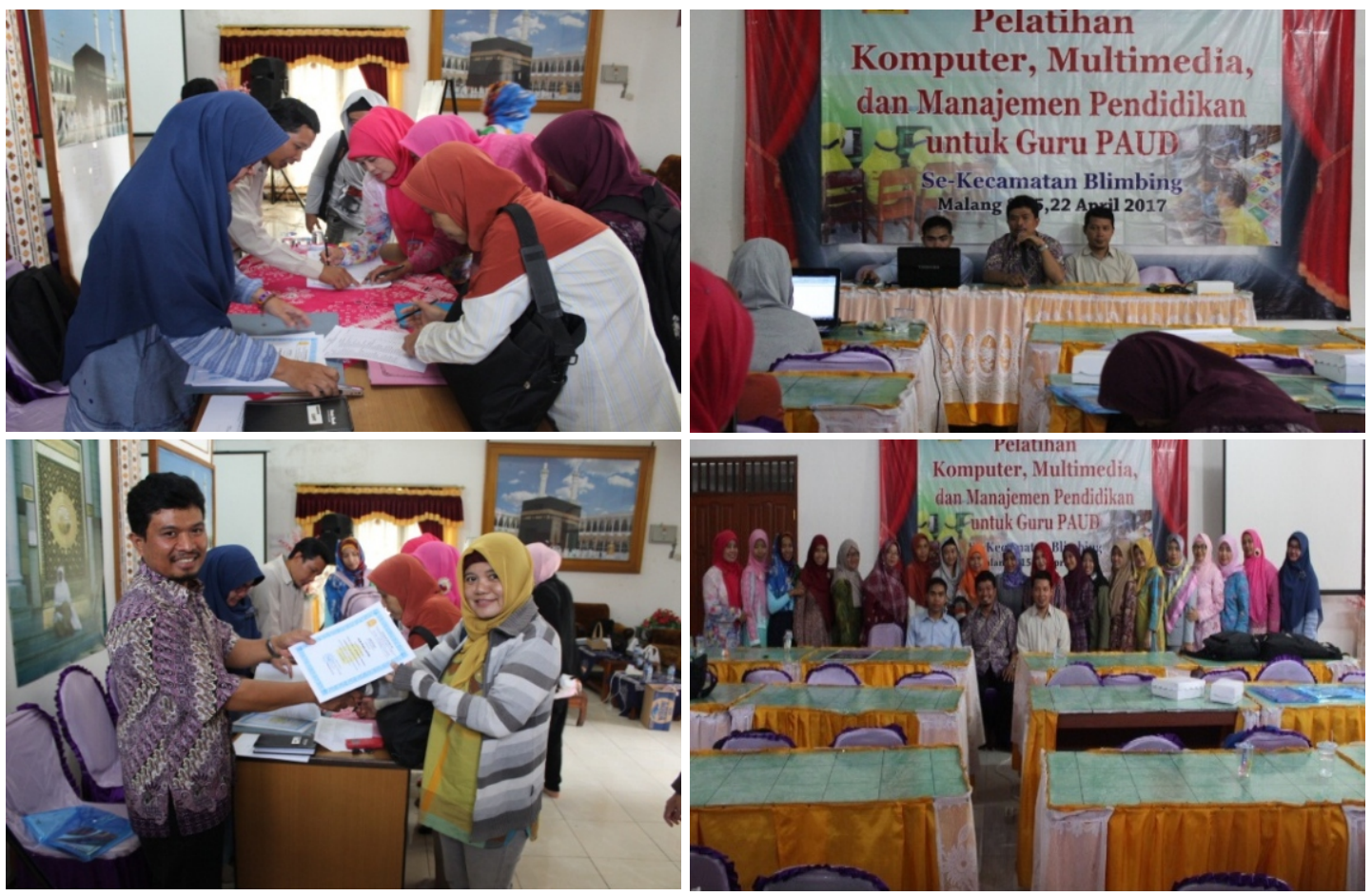

Gambar 6. Upacara penutupan dan penyerahan sertifikat pelatihan

\section{DAMPAKDAN MANFAAT}

Kegiatan PkM berupa Pelatihan Komputer dan Multimedia ini sangat bermanfaat bagi Guru PAUD di wilayah Kecamatan Blimbing Kota Malang, karena setelah menyelesaikan pelatihan, skill mereka dalam hal komputer multimedia meningkat. Indikatornya mereka dapat membuat surat menyurat disertai nama dan alamat surat secara otomatis, membuat laporan keuangan berbasis komputer, membuat presentasi pengajaran dengan power point dan mampu mengoperasikan LCD proyektor, sehingga sangat membantu Guru PAUD dalam mengembangkan pengajaran di sekolahnya masing-masing. 
Nurhadi, Peningkatan Kompetensi Mengajar Guru-Guru Paud...

\section{KESIMPULAN}

Berdasar pembahasan terhadap hasil kegiatan PkM, dapat disimpulkan bahwa kegiatan PkM berupa Pelatihan Komputer dan Multimedia ini sangat diminati oleh Guru PAUD, terbukti dari jumlah peserta yang melebih target (dari 20 peserta menjadi 30 peserta). Rata-rata peserta dapat mengerjakan tugas praktek dengan baik, dan menyatakan senang dan antusias dalam mengikuti pelatihan, bahkan menginginkan pelatihan lanjutan, sehingga dapat disimpulkan bahwa peserta pelatihan ini sudah berhasil menyerap materi pelatihan dengan baik dan pelatihan ini telah dilaksanakan dengan sukses.

\section{UCAPAN TERIMAKASIH}

Ucapan terimakasih disampaikan kepada pihak-pihak yang telah mendukung terselenggaranya kegiatan PkM ini, baik yang bersifat materiil maupun non materiil, yaitu: UPT P2M Polinema, Himpaudi Blimbing, dan PKBM Zamzam.

\section{REFERENSI}

Anonim, 2013, Cara Membuat Mail Merge pada MS Word dengan Data dari Excell, dari http://www.belajarexcel.info/2013/09/cara-menggunakan-mail-merge.html, diakses pada 16 Januari 2017

Anonim, 2015, Contoh Laporan Keuangan Sederhana dengan Excel 2013, dari https://excelku.com/2015/08/16/contoh-laporan-keuangan-dengan-excel/, diakses pada 16 Januari 2017

Thovids, Mustofa, 2015, Cara Membuat Animasi Presentasi Powerpoint yang Menarik +

VideoTutorial,darihttps://www.google.com/search?q=komputer\&ie=utf8\&oe=utf8\#q=cara+mem buat + presentasi + dengan + ms + power + point +2013 , diakses pada 16 Januari 2017

Wahyu, myranto, 2011, Cara Merawat Projector \& macam macam kerusakan Projector,darihttp://anekaprojector.com/index.php?option $=$ com_content\&view $=$ articl\&id= 420 : c a r a - m e r a w a t-project o r - a - m a c a m- m a c a m-kerus a k a n projector\&catid $=1:$ info\&Itemid $=2$, diakses pada 16 Januari 2017 